\section{THU0134 LEFT VENTRICULAR (LV) DIASTOLIC DYSFUNCTION ASSOCIATES WITH SYSTEMIC INFLAMMATION IN RHEUMATOID ARTHRITIS (RA)}

${ }^{1} \mathrm{MJ}$ Banks, ${ }^{2} \mathrm{~F}$ Ahmed, ${ }^{2} \mathrm{EJ}$ Flint, ${ }^{2} \mathrm{PR}$ Forsey, ${ }^{3} \mathrm{PA}$ Bacon, ${ }^{1} \mathrm{GD}$ Kitas. ${ }^{1}$ Rheumatology; ${ }^{2}$ Cardiology, Dudley Group of Hospitals NHS Trust, Dudley; ${ }^{3}$ Rheumatology, University of Birmingham, Birmingham, UK

\subsection{6/annrheumdis-2001.1036}

Background Abnormal diastolic LV filling is an early marker of cardiovascular disease and death. In the general population, it associates with hypertension, LV hypertrophy or ischaemia. A high prevalence has been reported in RA and other inflammatory conditions (up to 40\%), even after exclusion of patients with known, relevant cardiovascular pathology. Its cause and significance in inflammatory conditions remains unknown.

Objectives To identify the causes of diastolic LV dysfunction in RA.

Methods 39 random RA out-patients were assessed. LV filling: LV inflow Doppler in expiration by Echodoppler, with 5 measurements of isovolumetric relaxation time (IVRT), deceleration time (dte) and E:A ratio. Cardiac causes (BP, LVH, IHD ? age), Rose Questionnaire, examination, ECG, adenosine-stressed myocardial perfusion SPECT imaging. RA-related causes: acute phase response (current and mean ESR, CRP); cytokines (TNFa, Il-1b, Il-6); endothelial factors (vWF, ACE); Steroids: $>7.5 \mathrm{mg}$ Prednisone for $>6$ months; extra-articular disease. Statistics: Linear and multiple logistic regression as appropriate.

Results Age correlated significantly with IVRT $(\mathrm{r}=0.444, \mathrm{p}=$ $0.005)$, dte $(r=0.495, p=0.003)$, and $E: A$ ratio $(r=0.67, p$ $=0.0001)$. Mean ESR correlated with IVRT $(\mathrm{r}=0.324, \mathrm{p}=$ 0.04), Mean CRP with E:A ratio $(\mathrm{r}=0.305, \mathrm{p}=0.05)$, Il-6 with E:A ratio $(\mathrm{r}=0.34, \mathrm{p}=0.05)$, vWF with IVRT $(\mathrm{r}=$ $0.346, p=0.03)$ and $\mathrm{E}: \mathrm{A}$ ratio $(\mathrm{r}=0.331, \mathrm{p}=0.04)$. E:A ratio was significantly lower in those on steroids. Multiple regression showed age and mean ESR to independently predict IVRT. vWF was collinear with mean ESR for IVRT. Age, Il-6, and mean CRP were independent predictors of E:A ratio. vWF and steroids were collinear with mean CRP for E:A ratio. Hypertension, LVH, IHD, BMI, RA duration and extra-articular features did not associate with LV filling in RA. The association of LV filling with inflammatory mediators remained significant even after correction for age.

Conclusion The association of worsening LV filling with inflammatory burden rather than established cardiovascular causes in $\mathrm{RA}$ is an interesting new observation. It may explain the previously reported high prevalence of abnormal LV filling in RA and other inflammatory conditions and may be due to direct cytokine effects on the myocardium.

\section{THU0135 CARDIAC INVOLVEMENT IN RHEUMATOID ARTHRITIS (RA). HAS IT CHANGED?}

${ }^{1} \mathrm{MJ}$ Banks, ${ }^{2} \mathrm{~F}$ Ahmed, ${ }^{2} \mathrm{EJ}$ Flint, ${ }^{2} \mathrm{PR}$ Forsey, ${ }^{3} \mathrm{PA}$ Bacon, ${ }^{1} \mathrm{GD}$ Kitas. ${ }^{1}$ Rheumatology; ${ }^{2}$ Cardiology, Dudley Group of Hospitals NHS Trust, Dudley; ${ }^{3}$ Rheumatology, University of Birmingham, Birmingham, UK

10.1136/annrheumdis-2001.1037

Background Rheumatoid Heart Disease (RHD) (pericarditis, myocarditis, endocarditis) has been reported in 30-40\% of RA patients in several echocardiographic studies conducted before the era of aggressive, early therapy with disease-modifying drugs (DMARDs).
Objectives We assessed whether the recent therapeutic trend of early DMARD therapy has had an impact on the prevalence of cardiac complications of RA, compared with historical controls.

Methods 52 RA out-patients (19 males, 33 females) with a mean disease duration of 11.7 yrs who had received DMARD therapy within 12 months of symptom onset (6 months since diagnosis) were assessed echocardiographically. Pericardial disease was defined as pericardial thickening $(>5 \mathrm{~mm})$ or effusion. Endocardial disease was defined as either mitral or aortic valve thickening or calcification.

Results Endocardial disease was seen in 12 (23.1\%), pericardial disease in $11(21.2 \%)$, left ventricular hypertrophy (LVH) in 24 (46\%). Left ventricular systolic function was abnormal in 3 patients $(6 \%)$ due to regional wall motion abnormalities due to previous myocardial infarction. Assessment of myocardial disease was confounded by the high prevalence of LVH. There was no significant difference between males and females. Historical controls are shown in the Table 1.

\begin{tabular}{|c|c|c|c|c|}
\hline & Number & $\begin{array}{l}\text { Endocardial } \\
\text { disease }\end{array}$ & $\begin{array}{l}\text { Pericardial } \\
\text { disease }\end{array}$ & $\begin{array}{l}\text { Systolic } \\
\text { dysfunction }\end{array}$ \\
\hline Mody et al. 1987 & 84 & $10 \%$ & $8 \%$ & $6 \%$ \\
\hline $\begin{array}{l}\text { Macdonald et al. } \\
1977\end{array}$ & 51 & - & $35 \%$ & $8 \%$ \\
\hline Bacon et al. 1974 & 44 & $34 \%$ & $34 \%$ & - \\
\hline $\begin{array}{l}\text { Prackash et al. } \\
1973\end{array}$ & 16 & - & $45 \%$ & - \\
\hline
\end{tabular}

Conclusion The prevalence of pericardial and endocardial disease appears lower than that of historical controls. As with other extra-articular disease manifestations, earlier use of DMARDs may have had an advantageous impact on the development of cardiac complications of RA.

\section{THU0136 CONFIDENCE IN THE DIAGNOSIS OF EARLY RHEUMATOID ARTHRITIS: A PROSPECTIVE FOLLOW-UP OF 270 EARLY-ARTHRITIS PATIENTS}

${ }^{1} \mathrm{JM}$ Berthelot, ${ }^{2} \mathrm{~A}$ Saraux, ${ }^{2} \mathrm{C}$ Le Henaff, ${ }^{3} \mathrm{G}$ Chalès, ${ }^{4} \mathrm{JB}$ Thorel, ${ }^{5} \mathrm{~S}$ Hoang, ${ }^{2} \mathrm{D}$ Baron, ${ }^{2} \mathrm{P}$ LeGoff, ${ }^{2} \mathrm{P}$ Youinou. ${ }^{1}$ Rheumatology Unit, Hôtel-Dieu, CHU Nantes, Nantes; ${ }^{2}$ Rheumatology Unit, Hôpital de La Cavale Blanche, CHU Brest, Brest; ${ }^{3}$ Rheumatology Unit, Hôpital Sud, CHU Rennes, Rennes; ${ }^{4}$ Rheumatology Unit, CHD, Lorient; ${ }^{5}$ Rheumatology Unit, CHD, Vannes, France

\subsection{6/annrheumdis-2001.1038}

Background The treatment of early rheumatoid arthritis (RA) should not be delayed. However, aggressive therapy is often introduced only when rheumatogists feel confident enough in their diagnosis of RA.

Objectives We sought the confidence of both office-based-rheumatologists (OBR) and a college of 5 experts in their diagnosis of early-RA.

Methods 270 patients with early-onset ( $<1$ year) arthritis were prospectively followed-up for $29 \pm 11$ months. At final examination, OBR and a college of 5 experts rated their confidence in the diagnosis of RA on $0-10$ and 1-4 analogue scales respectively.

Results $35 / 270$ patients (13\%) were still unclassified by their OBR. RA was diagnosed in 114 (42\%), spondylarthropathy in 